\title{
Fuel theft in road freight transport: understanding magnitude and impacts of anti-theft devices
}

\section{Luca Urciuoli ${ }^{1,2}$ (D)}

Received: 18 October 2019 / Accepted: 14 February 2020/Published online: 8 June 2020

(C) The Author(s) 2020

\begin{abstract}
Fuel is one of the most important cost items that road carriers include in their freight rates. It has been demonstrated that unexpected changes of fuel costs influence mobility, logistics performance and profit margins. Experts believe that criminal organizations are targeting the transport sector to steal, smuggle and contraband diesel fuel. Today, very little data exist across the scientific community, depicting this phenomenon. Hence, the goal of this study is to shed light on the problem of diesel theft in freight transport, with a focus on determining its magnitude, its geographical displacement, main modus operandi, and potential impact of protective measures. A survey is developed and used to collect data from members of the Swedish Association of Road Transport companies. Replies from 189 companies are collected (18.9\% response rate) and analyzed. Overall, this study unveils that about 150,225 1 of fuels have been stolen from Swedish road carriers. In addition, data reveals that only a minority of these companies are affected by the problem, opening the hypothesis that attacks are geographically concentrated in areas where transport/logistics operations are intense. Several devices are available today to avoid fuel theft. Among those, tank gauging and radar-based technologies are preferred by companies, in view of their deterring effects.
\end{abstract}

Keywords Transport security $\cdot$ Fuel theft $\cdot$ Transport security measures $\cdot$ Supply chain security

Luca Urciuoli

urciuoli@kth.se

1 KTH Royal Institute of Technology, Department Industrial Engineering and Management, Stockholm, Sweden

2 MIT-Zaragoza Logistics Center, Zaragoza, Spain 


\section{Introduction}

Transport security refers to criminal acts against transportation systems, including both freight and passenger systems (Reggiani 2013; Sternberg et al. 2012). Criminals could steal cargo, fuel or expensive parts from vehicles. They could exploit transport vehicles for immigrant smuggling or contraband of prohibited items. Trucks or sea vessels transporting dangerous goods could be hijacked and detonated in sensitive areas in cities or transport terminals like airports, train stations, seaports etc. (Männistö et al. 2014; Talarico and Zamparini 2017).

Experts have tried to estimate the costs of transport insecurity. The European commission has estimated that theft of cargo from road and rail transport systems amount to some $€ 8$ billion per year (Talarico and Zamparini 2017). However, many are convinced that these figures could be higher. When security accidents happen it is unlikely that companies or drivers report them to the authorities (van den ENGEL and PRUMMEL 2007). Even when reported, costs do not comprehensively account collateral damages provoked by security accidents (Urciuoli 2016).

Transport is the backbone of our societies ensuring the movement of people and freight. A terror attack against an important transport hub, e.g. airport, bus terminal or train station, can hinder commuting and instill fear and retain public confidence, impacting the way people travel (Reggiani 2013). Industries and other public offices will ultimately pay the costs of less effective travelling of their employees. Likewise, security issues in freight transport end up disrupting supply chains. A vehicle can breakdown, or the driver could be injured or killed (IRU 2009). Shippers will also be affected since they will lose the cargo and the buyer may risk a stock out, leading to lost sales and unfulfilled customer demand. In addition, costs increase due to investigations to be performed, in order to determine liabilities, motivate insurance claims and determine premiums increment (Chen et al. 2005; Crone 2007; Sternberg et al. 2012) (Burges 2012; EUParliament 2007; Urciuoli 2016; Viswanadham and Gaonkar 2008).

Among security threats, theft of fuel is an important crime against the transport sector that has not been adequately studied and analyzed by researchers and practitioners. Anecdotal evidence tells that the problem exists and it could have significant consequences, e.g. vehicle breakdown, lost/late delivery, customer satisfaction etc. (Geddie and Khasawneh 2018). If fuel costs increase unpredictably, expected revenues could be lost, shrinking companies' marginal profits and reducing market competition. Logistics efficiency could also be affected. When fuel prices increase, some carriers may decide to decrease commercial speed, or alter the number of vessels deployed per loop, with evident implications on liner services delivery time and service quality (Corbett et al. 2009; Notteboom and Vernimmen 2009). Fuel theft is one of the reasons that is driving national transport administrations in Europe to increase the number of secure parking places for commercial vehicles (EU 2010; Regeringen 2018; TAPA 2018).

Managerial practices could be tailored to prevent and optimally counteract fuel theft (Urciuoli and Hintsa 2016a). Likewise, risk management approaches can support managers classifying and ranking the impact of different types of technologies (Chopra and Sodhi 2004; Giannakis and Louis 2011; Lun et al. 2008). However, without knowledge about the magnitude of the problem and the efficacy of existing security measures, companies may struggle to properly assess the problem and adopt solutions (Urciuoli 2011). Hence, the following research questions are formulated: 
- What is the magnitude of diesel theft in Sweden?

- What anti-theft devices can road carriers adopt to counteract fuel theft?

The goal of this study is to shed light on the problem of fuel theft from road carriers in Sweden. More specifically, by means of a survey performed with Swedish transport carriers this paper aims 1) to enhance understanding of fuel theft from road carriers, and 2) to review the efficacy of selected technologies to deter fuel theft.

The structure of this paper is the following: after the introduction, literature related to transport security, fuel theft modus operandi and existing protective measures to counteract transport security problems is expounded. Next, the methodology, consisting of a survey gathering data from Swedish road carriers is expounded. Finally, the results from the survey are depicted, followed by concluding remark and a discussion of scientific and practical implications for managers.

\section{Transport security and fuel theft}

Transport security issues are being debated on national and international level, especially in view of the new policies and regulations drafted to counteract terrorism, or in general to prevent any threats to national security originated from the transport system (Reggiani 2013). These actions have been put into place by governments and private actors, mostly in view of the tragic attacks in New York September 2001 (Lun et al. 2008). The attacks demonstrated the vulnerability of the aviation sector, however, it was soon discovered that both passenger and freight systems were extremely vulnerable (Sheffi 2001a). Public transport hubs or vehicles could be targeted by terrorists in order to provoke deaths and injuries, while the freight sector could be targeted to smuggle terrorists, weapons for mass destruction, manipulate its content etc. (Anderson 2007; Lee and Wang 2005).

Theft from transport means or infrastructure is a known problem to both research and practitioners (Sternberg et al. 2012; Wu et al. 2017). Theft of cargo, or vehicles or part of their components can imply significant costs, up to six times the value of the cargo itself (Burges 2012). Lun et al. (2008) explain that business organizations that are not able to deploy appropriate technologies to enhance visibility, may suffer financial losses due to theft. Typically, electronic products or high-value goods are being targeted by criminals, with countries like Mexico, Brazil, South Africa, USA and Russia ranking on the top of the available statistics (Wu et al. 2017).

Fuel theft concerns the misappropriation of fuel from tanks available at fuel stations, refineries or from the tanks of stationed transport vessels. For instance, in Singapore it has been estimated that over \$40 million fuel has been stolen from Shell refineries (Geddie and Khasawneh 2018). A study performed by the International Road transport Union's (IRU) in the UK indicates 894 events, with a corresponding amount of stolen fuel of about $\sim 320,0001$ over a period of 6 months, i.e. about 5331 stolen per company. Fuel theft from road transport is difficult to estimate, since many of these criminal activities goes unreported. Reasons for not reporting are part of the market constraints and heavy competition that ultimately incites drivers or transport carriers to solve financial losses internally (Urciuoli 2016). To give an example about the modus operandi for stealing fuel from tanks, Fig. 1 shows a Y-type pick up tube (sometimes 
called T-type) (Bennett 2012). It is a dual fuel tank arrangement, which is used to increase fuel capacity as well as distribute weight uniformly. To steal fuel from the tank arrangement of a light or heavy duty truck the options are the following:

- Tamper/remove fuel cap. Tampering/removing the fuel cap is the easiest way to access the fuel in the tank. Even if provided with locking, it seems that generic cap keys can be simply purchased on the internet for few euros. These gas cap keys have a double ended design allowing to open gas caps of almost any vehicle. Once the cap has been removed (item 5, Fig. 1), fuel is simply siphoned by inserting a flexible tube in the tank and blowing air into it. Overall, the complexity for such an operation is low so as the costs and time to open a fuel cap and siphon.

- Remove vent cable/valve and siphon. The vents (item 6, Fig. 1) are more difficult to reach, but if accessed the hose can be removed manually, the vents easily screwed out and ultimately fuel can be stolen through siphoning.

- Remove welded fuel pick-up tubes. Pick-up tubes are normally welded in the tank and difficult to reach and remove (but locations may vary for different trucks and tank styles). Yet, the pick-up tubes can be cut and dropping fuel collected (items 2 and 3, Fig. 1).

- Tank puncturing. Puncturing the tank (item 4, Fig. 1) and syphoning or simply collecting dropping fuel.

\section{The illicit trading of fuel}

Stolen goods can be sold illicitly directly to consumers or even retailers. Nowadays, shadow markets exist and have major focus on the smuggling of tobacco and drugs

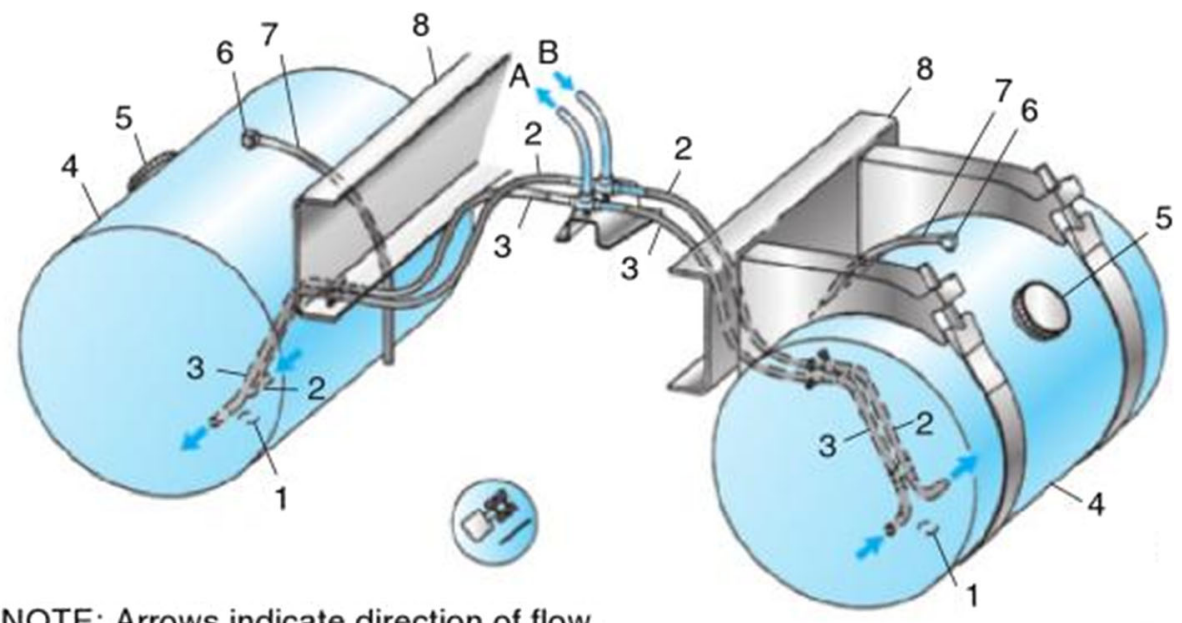

NOTE: Arrows indicate direction of flow.
A. To fuel pump
1. Drain
$B$. From engine
2. Supply (suction) line
3. Return line
4. Fuel tank
7. Vent line
5. Fuel cap
8. Frame rail
6. Vent

Fig. 1 Dual fuel tank arrangement (S. Bennett 2012) 
(Talarico and Zamparini 2017). Customs and law enforcement agencies are working to enhance their cooperation and sharing of information about supply chains in order to detect and seize smuggled substances. However, limited evidence suggests that a shadow market of fuel may exist. Studies performed in Greece indicates that fuel is stolen through a sophisticated combination of modus operandi against supply chains, e.g. product diversion, adulteration, fraud, corruption, and thereby shipped to hidden markets and sold illicitly (Bitzenis and Kontakos 2014). Researchers have suggested that the increasing prices of the energy sector directly affect the growth of the shadow economy of stolen fuel as well as corruption episodes (Ageeva and Suslov 2009; Bitzenis and Kontakos 2014).

Illicit trade of fuel implies several consequences for companies and societies. The private sector, i.e. transport carriers, not only lose the fuel but it can experience vehicles breakdowns, delays, penalties and drivers could be injured or even killed during an attack (Chen et al. 2005; Sternberg et al. 2012). In addition, quality of transport services could be lowered. In this aspect, fuel shortage or its increased costs, can lead to decreased commercial speed, or alter the number of vessels deployed in transport loops (Corbett et al. 2009; Notteboom and Vernimmen 2009). In other extreme cases, when fuel theft is perpetrated against fuel stations, the local community can experience shortages with consequent disruption of transport operations (Taye 2018). Finally, when the stolen fuel is sold illicitly to black markets, governments and societies are also penalized, due to the loss of revenues from customs duties and taxes generated from the sale of fuel.

\section{Protective measures}

Improving security means allocating investments or changing strategies or practices of doing business. Therefore, transactions costs may increase as well as lead times to move cargo, worsening overall transport and supply chain performance (Urciuoli and Hintsa 2016b; Wu et al. 2017). Types of measures that can be used today to avoid or mitigate security threats in transportation can be classified as managerial strategies, operative routines and technical systems (Urciuoli 2010). Managerial approaches include strategies to 1) create redundancy of assets and resources in an organization (increasing flexibility and capacity), 2) share risks in transport contracts, 3) establish a Chief Security Officer (CSO), and 4) comply to security certifications, e.g. TAPA EMEA, ISO/PAS 17712:2006, ISO 28001:2006, Authorized Economic Operator, C-TPAT etc. (Sheffi 2001b; Simchi-Levi et al. 2002). Operative routines refer to tactical or short-medium term solutions aiming to secure companies' transport operations. For instance, companies may use maps with crime hot-spots and plan their routes in order to avoid them. Previous research demonstrates that transit types and shipping destinations are essential factors determining cargo loss severity (Wu et al. 2017). Fennelly (2012) points out the importance of avoiding waiting times outside receiving terminals, where the cargo is more vulnerable and could be exposed to the risk of theft. In this aspect, JIT techniques could lead to improved security, given that carriers can quickly enter terminals to load/unload cargo. Likewise, transport companies may introduce practices for vetting drivers or check identities and transport documentation following the cargo 
etc. Other operative routines that can be useful to prevent fuel theft are mentioned in available security certification systems and include parking trucks in alarmed depots, contract security guards or park in secure/manned places (see for instance TAPA (2017)). Finally, technical systems consist of sensors or mechanical systems to deter or harden a target. Known systems to deter fuel theft include mechanical locks, anti-syphoning tank inlets, valves to stop attempts to siphon fuel from tanks. Other solutions can be installed directly inside tanks, e.g. waterproof cameras, providing evidence of fuel theft, or sensors measuring fuel consumption. In the latter case, a fleet management software correlates amount of kilometer travelled with fuel consumptions measured in the tank and thereby detect any abnormal deviation.

\section{Methodology}

Several different data sources have been used (literature, interviews, and a survey), in order to allow for data triangulation. This study started with a brief literature review in order to develop an overall understanding of supply chain and transport security, illicit trading of fuel and existing protective measures. The latter aspect was further elaborated by reviewing literature about the design of fuel tank systems as well as websites and magazines listing fuel anti-theft devices or solutions.

The review was followed by in-depth semi-structured interviews with selected Swedish and European experts in diesel theft. Interviewees were selected in view of their level of expertise in road transport and the roles covered in the fuel theft discussion. The list below, summarizes the interviewees' roles and expertise:

- experts in diesel theft from the Swedish police forces, transport security group established in the region of Västra Götaland.

- developers of solutions for commercial vehicles from Volvo Trucks.

- 1 expert in diesel theft from the International Road Transport Union (IRU).

- 1 expert from the German freight forwarders association DLSV (Deutscher Speditions- und Logistikverband e.V.).

- 1 expert from the Freightwatch International association.

- 1 expert from the Swedish Association of Road Transport Companies.

- 2 academic experts in transport/supply chain security.

Results were gathered, analyzed and a survey instrument was developed accordingly.

\section{Instrument development and data collection}

The interviews were used to develop and review the survey questions and thereby to modify and improve the questionnaire's wording and alignment with the scope of the study. The survey instrument was made of the following blocks:

- Demographics data. This section included questions about the type of transport activities performed by companies, number of transport assignments, covered distance annually and fleet size. 
- Fuel theft frequency, magnitude and modus operandi. Open questions allowing for numerical replies were used to assess frequency and magnitude of fuel theft. Regarding the modus operandi used to steal diesel from trucks, the survey asked to grade five different techniques on a Likert scale from 1 (Never) to 5 (More than 30 times a year):

- Drill Tank. Drill holes in the fuel tank and extract diesel.

- Violence. Use force and/or violence against driver in order to force him/her to open the tank lock and hand over the diesel to criminals.

- Tamper fuel cap. Tampering of the fuel tank lock and syphoning of diesel (e.g. manual or motor pump syphoning).

- Cut/remove cables. Access and syphon diesel from fuel tank by cutting the cables connecting the fuel tank to the engine (fuel pick up tubes) or the emission evaporative system (vent valve and cables).

- Insider. The driver fuels illicitly without the approval or knowledge of the company.

- Analysis of protective measures. The impact of the protective measures was measured with 5-points Likert scale, from 1-Very Bad to 5- Very good, with a neutral point in the middle, 3 neither good nor bad.

The questionnaire was published on a web-based platform for surveys and road transport carriers were invited to participate to the study. The invitation was sent to a randomly selected sample of 1000 medium-large road transport companies (based on number of employees) that are members of the Swedish Association of Road Transport Companies (Sveriges Åkeriföretag). The Swedish Association of Road Transport Companies is a trade organization for the Swedish haulage industry. It fosters the profitable development of the haulage industry, assist in lobbying and monitor the haulage industry's interests nationally and internationally. ${ }^{1}$ Assuming a $95 \%$ confidence level and $p=50 \%$, the sample size of 1000 companies on a population of about 7000 (size of Sveriges Åkeriföretag database) yield a confidence interval of approximately $\mathrm{CI} \pm 3 \%$ (Cochran 2007). A reminder to reply to the survey was sent to all companies two weeks after the first request. When the survey was closed, a total of 189 replies was collected, corresponding to a response rate of $18.9 \%$.

\section{Data analysis, validity and reliability}

The data collected is merely for descriptive and explorative scope. Hence, the analysis focuses on computations of means, standard deviations and correlations. An early-late respondent's analysis was carried out to determine whether there were significant differences and potential biases in the results. Independent sample t-tests unveiled that there are significant differences between early and late respondents in terms of amount of diesel theft incidents and liters of diesel stolen $(p<0.01)$ and in terms of annual turnover of companies $(p<0.05)$. Hence, companies that answered earlier are of medium-large size (in terms of annual turnover) and have a higher amount of diesel theft incidents $(\mathrm{M}=2.6)$ and liters stolen $(M=1187$ ) than those answering later (amount of incidents $M=1.3$, liters stolen $M=434$ ). This raises the hypothesis that the perception of the importance of the

\footnotetext{
${ }^{1}$ http://www.akeri.se/om-oss
} 
problem was a significant incentive to answer the survey. This was also confirmed by follow-up interviews with 14 companies randomly selected from the group of nonrespondents. All the companies confirmed that the reasons for not answering the surveys were in order: 1) the limited magnitude of the problem within the company (very low or inexistent), 2) overlooking the email invitation and 3) not enough time to answer.

\section{Results}

The questionnaire was mainly replied by the owners or CEOs (Chief Executive Officers) of the companies. A great majority of the companies that replied to the survey has their main headquarters located in the region of Västra Götaland (20.63\%), followed by the regions of Stockholm (10.58\%), Gävleborg (7.94\%), Hallands (7.41\%), Värmlands (6.35\%), Skåne and Västerbottens $(5.82 \%)$. Other regions have less than $5 \%$ of respondents each (Fig. 2).

$34.22 \%$ of the companies have between 2 and 5 employees, $26.20 \%$ are one-man companies (1 employee), followed by companies with 6-10 employees (12.30\%). Only $5.88 \%$ have 51-249 employees (Fig. 3). In terms of magnitude of annual turnover, $47.87 \%$ of the companies have declare a turnover of SEK 1 to 5 million, followed by $17.55 \%$ with more than 20 million, $15.43 \%$ SEK 10-20 million, and 13.30\% SEK 5 to 10 million (Fig. 3).

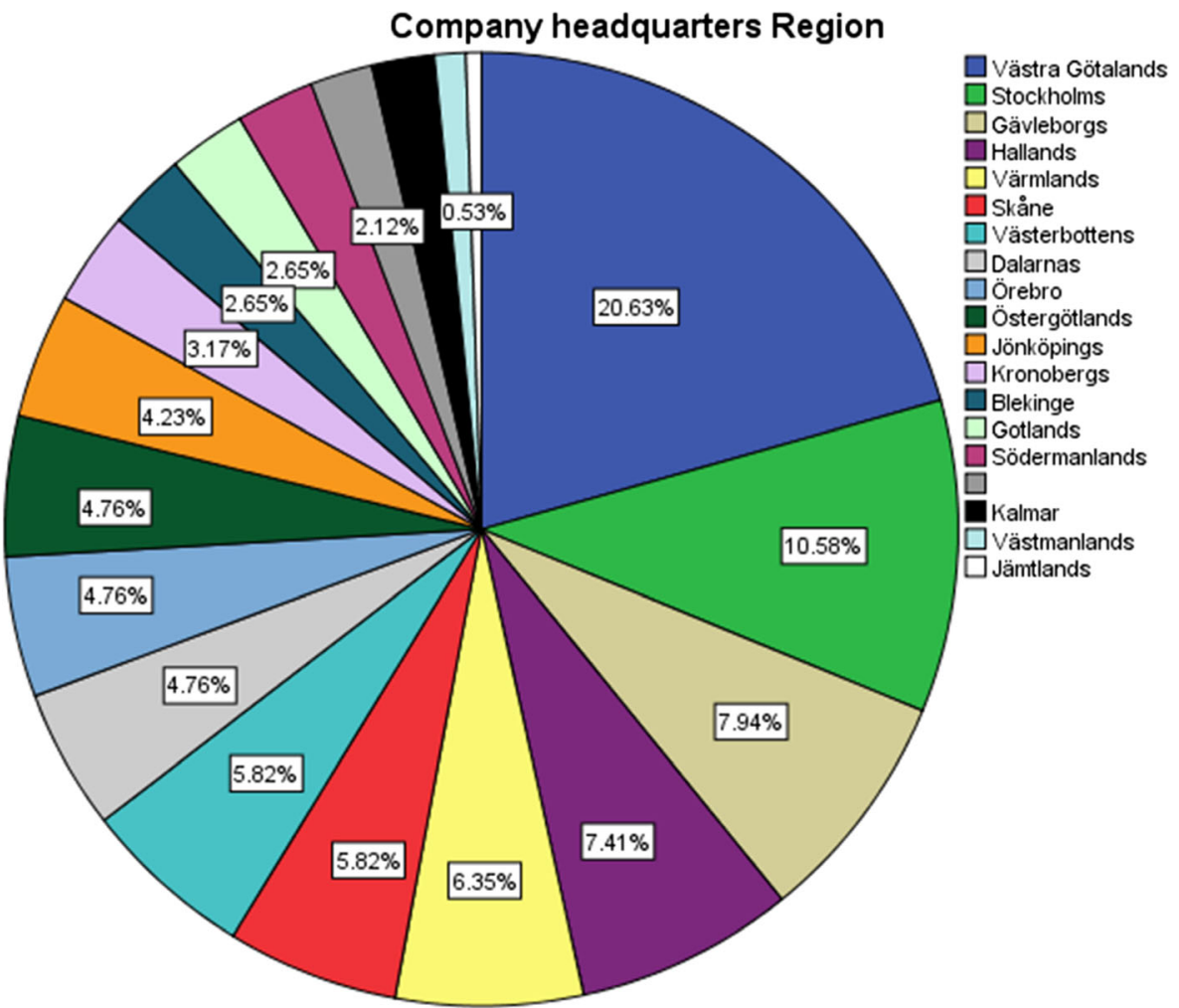

Fig. 2 Region of companies' headquarters $(n=189)$ 

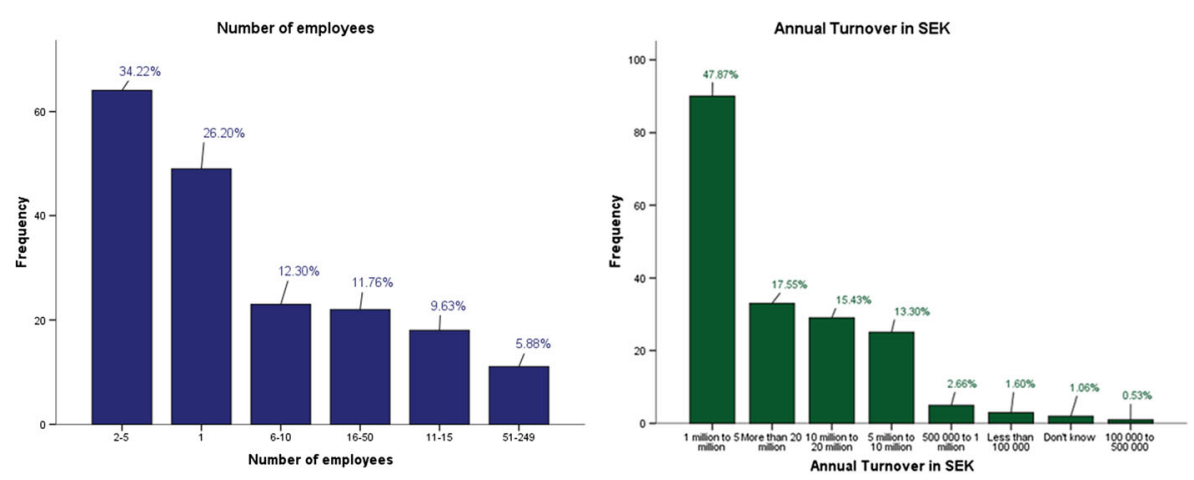

Fig. 3 Companies' numbers of employees and annual turnover in SEK

\section{Transport performance indicators}

On average, the companies own about 8 trucks (min 1 to max 140), performed 7277 transport assignments per year (min, 7 to $\max , 250,000)$ and covered a distance of about 95,337 km per truck (Table 1).

The Pareto diagram of the number of commercial vehicles owned shows that $80 \%$ of companies, own between 1 and 8 trucks. The remaining $20 \%$ has variable fleet sizes between 6 and 140 trucks (Fig. 4). A good majority, 80\% of the respondents, have covered distances between a minimum of 4000 Swedish miles $(40,000 \mathrm{~km})$ to a maximum of 20,000 Swedish miles $(200,000 \mathrm{~km}$ ) annually (Fig. 5). It is possible to deduct that type of transport assignments range from urban to regional and national ones.

Many of the companies distributes cargo on regional level $(\mathrm{M}=48.3 \%$, Std. Dev $=$ 37.66), followed by urban transport $(\mathrm{M}=25.9 \%$, Std. Dev. $=27.29)$ and closely by interregional transport assignments $(\mathrm{M}=24.57 \%$, Std. Dev. $=33.31)$. Only $6.17 \%$ of the companies perform international transport assignments $(\mathrm{M}=6.17 \%$, Std. Dev. $=$ 20.17) (Table 2).

\section{Number of incidents and liters stolen}

The variable measuring the amount of stolen diesel in one year shows that the companies that suffered diesel theft incidents, were stolen totally 150,225 1 of fuel. Each company on average lost almost 8001 of fuel $(M=799.07$, Std. Dev. $=2018.3)$. The magnitude of the standard deviation tells clearly that variation of stolen liters is high, rising to a worrying maximum of more than 20,000 1 stolen in a year (Fig. 6).

Table 1 Level of activity

\begin{tabular}{llll}
\hline & Mean (Std. deviation) & Minimum & Maximum \\
\hline Number of commercial vehicles & $8.59(17.74)$ & 1 & 140 \\
Number of transport assignments & $7277.90(27,526.40)$ & 7 & 250,000 \\
Average annual miles travelled per vehicle* & $9533.70(379.81)$ & 120 & 25,000 \\
\hline
\end{tabular}

*1 [Swedish mile] $=10[\mathrm{~km}]$ 


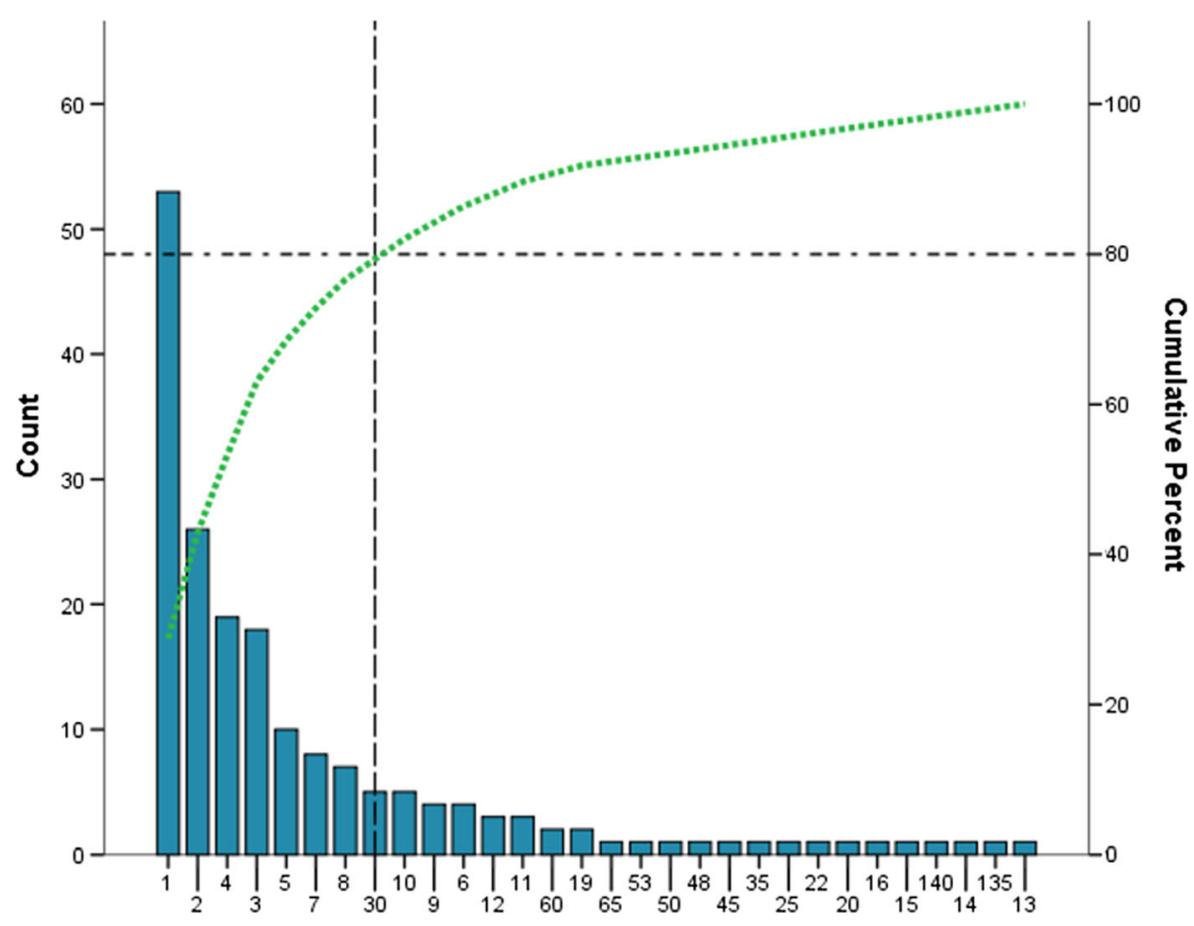

Number of commercial vehicles

Fig. 4 Pareto diagram number of commercial vehicles

Despite the high amount of fuel stolen, the frequency of accidents is limited to isolated cases, i.e. number of diesel theft experienced by the surveyed companies are on average almost 2 per year $(M=1.94$, Std. Dev.=3.24). 99 of the 189 surveyed companies experienced between 1 and 20 incidents, and 90 companies did not suffer any theft.

Further analysis shows that the number of commercial vehicles owned by companies correlates significantly with the amount theft incidents and liters stolen from the trucks $(p<0.001)$. this raises the hypotheses that the problem of diesel of theft is affecting larger companies, or similarly, companies owning larger fleets of vehicles.

\section{Frequency of Modus Operandi}

The analysis of the collected answers shows that the dominating modus operandi is tampering the fuel cap lock and syphoning the fuel from the tank (either manually or by means of a motor pump). About $45 \%$ the companies state that tampering the fuel cap has happened 1-5 times per year and 10.05\% 6-20 times per year. Only in few cases other modus operandi is used by criminals. Few companies $(0.15 \%)$ state that drilling and use of violence against drivers has been used to steal diesel (1 to 5 times per year). $3.1 \%$ of the companies answered that vent cables have been cut 1-5 times per year. Finally, fraud activities, e.g. refuel vehicle and private tanks, and debiting the whole amount to the company, are rare. $2.6 \%$ of replying companies declared that this happens $1-5$ times per year and only $0.5 \%$ of the respondents answered that the frequency is higher than 30 times per year.

Other modus operandi for stealing diesel from the company that were flagged by the respondents include the following: 


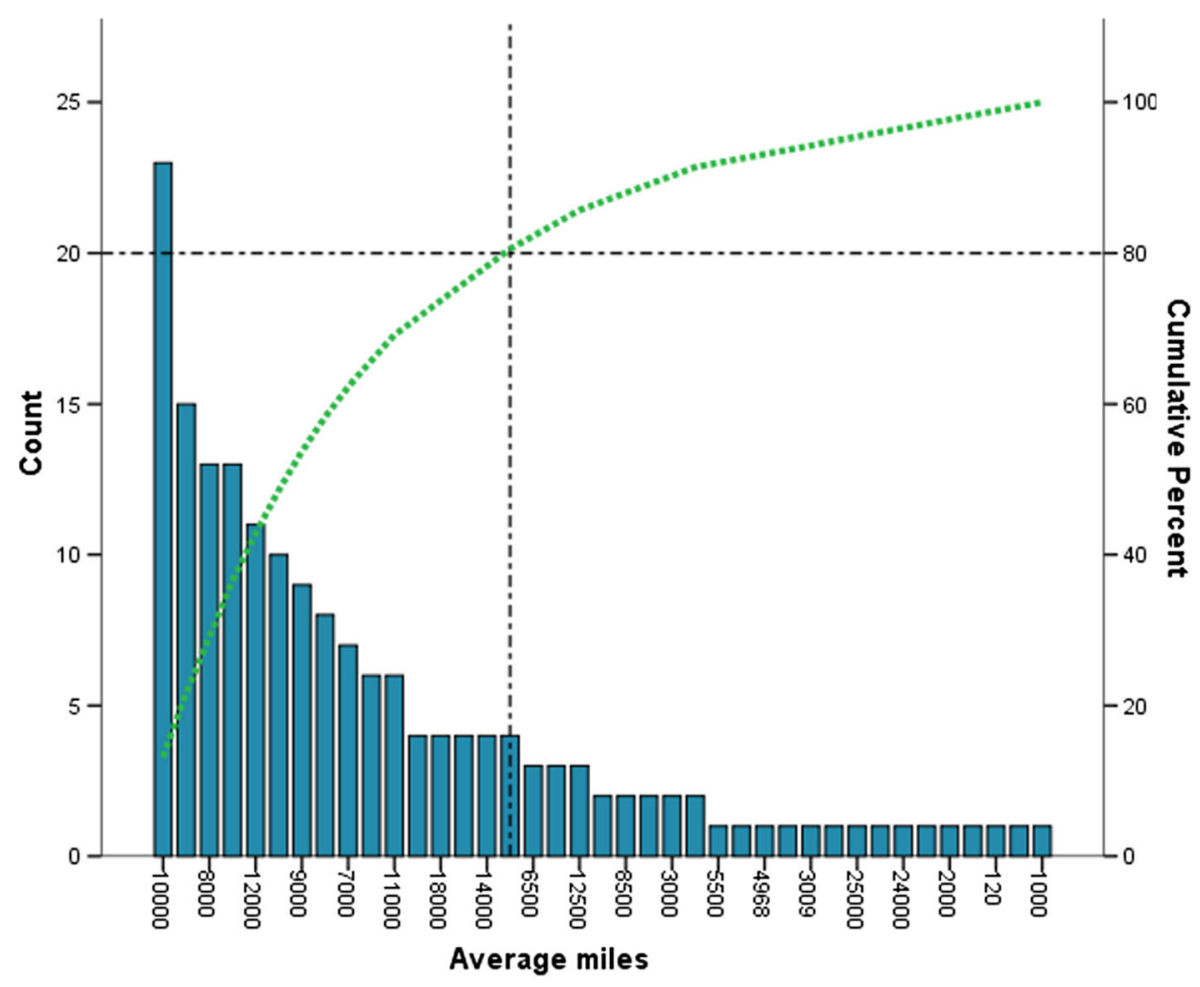

Fig. 5 Pareto diagram, average annual Swedish miles travelled per vehicle

- Credit card skimming. The credit card is swiped and stored in a database by using a small electronic device (skimmer). The skimmed credit card is illicitly used in diverse financial transactions, e.g. to purchase diesel from fuel stations.

- Tank forced. The fuel tank is opened by using a hammer or ax.

\section{Crime spots}

Analysis of diesel theft events per region, unveils that most diesel theft incidents is highly concentrated in few regions. In particular, $80 \%$ of the incidents are concentrated in Västra Götaland (103), Gävleborg (43), Stockholm (41), Jönköping (30), Örebro (29), Skåne (20) and Västerbotten (20) (Fig. 7).

Table 2 Average $\%$ of type of transport assignment

\begin{tabular}{lcc}
\hline & Mean & Std. Deviation \\
\hline \% Urban Transportation & 25.9 & 27.29 \\
\% Regional Transportation & 48.29 & 37.66 \\
\% Interregional Transportation & 24.57 & 33.31 \\
\% International Transportation & 6.17 & 20.17 \\
\hline
\end{tabular}



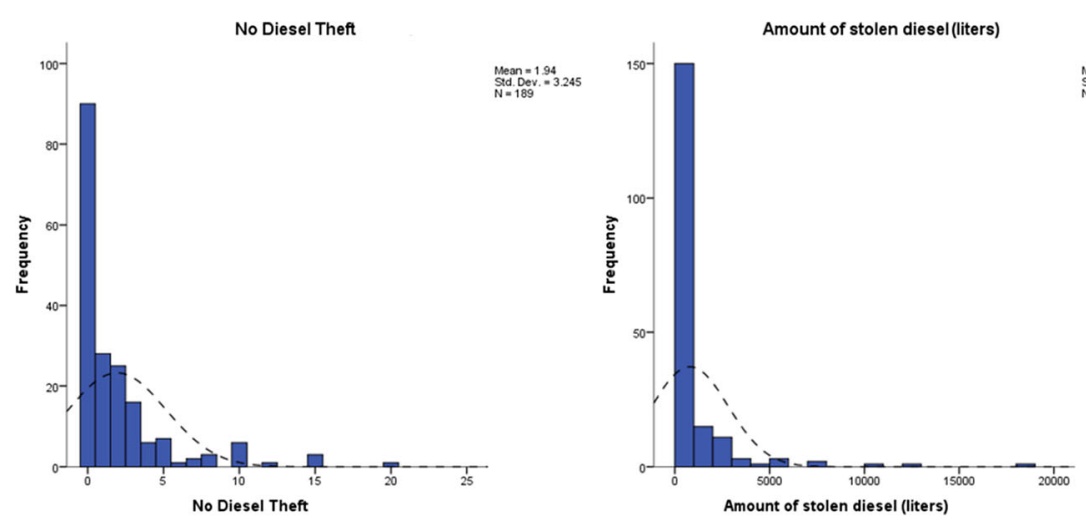

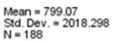

Fig. 6 Statistical distribution of amount of diesel thefts and stolen liters of diesel

Except for Västerbotten, the same regions explain the $80 \%$ of the whole amount of stolen diesel $(150,2251)$. By sorting on the liters of stolen diesel it is possible to observe that the regions affected are in order Stockholm (32,600 1), Västra Götaland (27,685 1), Kronoberg (19,250 1), Örebro (15,550 1), Gävleborg (11200), Jönköping (10,970 1), and Skåne (5200 1). Computing the ratio of liters of fuel stolen per incident, it is noticed that the Kronoberg region had the highest ration of stolen liters of fuel per incident (Fig. 7).

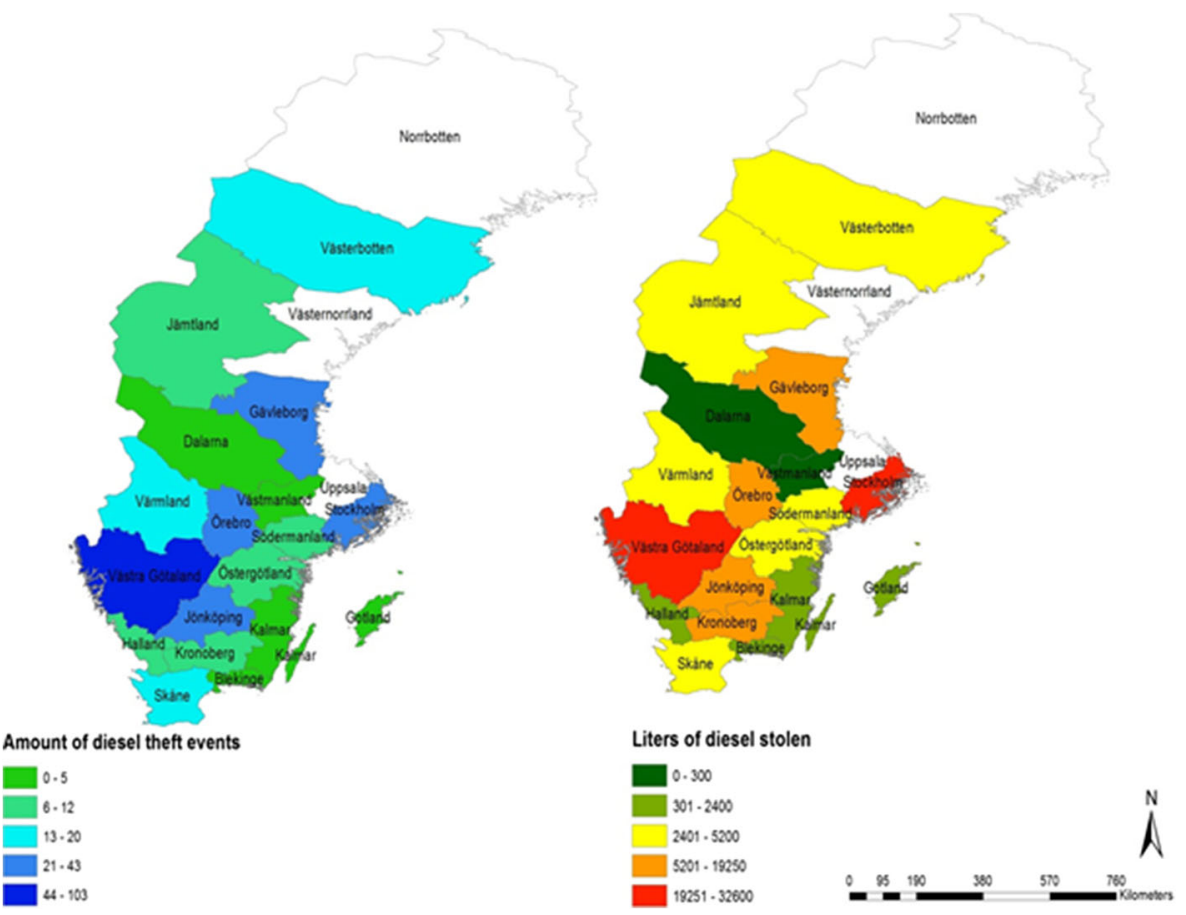

Fig. 7 Amount of diesel theft events and liters stolen per region 
Truck depots seem to be the preferred targets of criminals in order to gain access to vehicles and steal diesel from them (36\%). This location is followed by rest areas $(10.58 \%)$, customers' premises where cargo is loaded or unloaded $(7.94 \%)$, parking places close to drivers' home $(7.41 \%)$, roadside $(5.29 \%)$, fuel stations $(4.23 \%)$ and even secured parking (2.12\%) (Fig. 8).

\section{Security measures adopted}

The security measure that is mostly used by respondents consists of mechanical locks to protect the fuel tank lock from tampering and syphoning $(55.03 \%)$. A significant group of respondents is not using any of the security measures proposed in the questionnaire $(23.81 \%)$. The anti-syphoning tank inlet is also quite popular and is being used by about $23 \%$ of respondents, followed by camera-based devices remotely monitored $(10.05 \%)$, and web-based services monitoring travelled distance on liters of fuel tanked $(6.88 \%)$. Other less used solutions include fuel lock alarms, dyed fuel, radar (monitored centrally or by driver), tank gauging, cameras (monitored centrally or by driver) (Fig. 9).

Other non-technical security measures that were suggested by companies include:

- Keep trucks locked in an alarmed garage/depot if the fuel tank is full.

- Plan transport assignments in a manner to avoid parking the truck with full tank. E.g. refuel when the transport assignment begins.

- Block access to fuel tank by parking close to other trucks or walls.

- Constantly monitor parking places.

- Use secured parking (e.g. manned).

- Avoid parking in isolated and dark places (e.g. roadside).

- Use (when possible) the trucks built-in crane to block access to the fuel tank.

- Reinforce with extra metal plates the fuel cap.

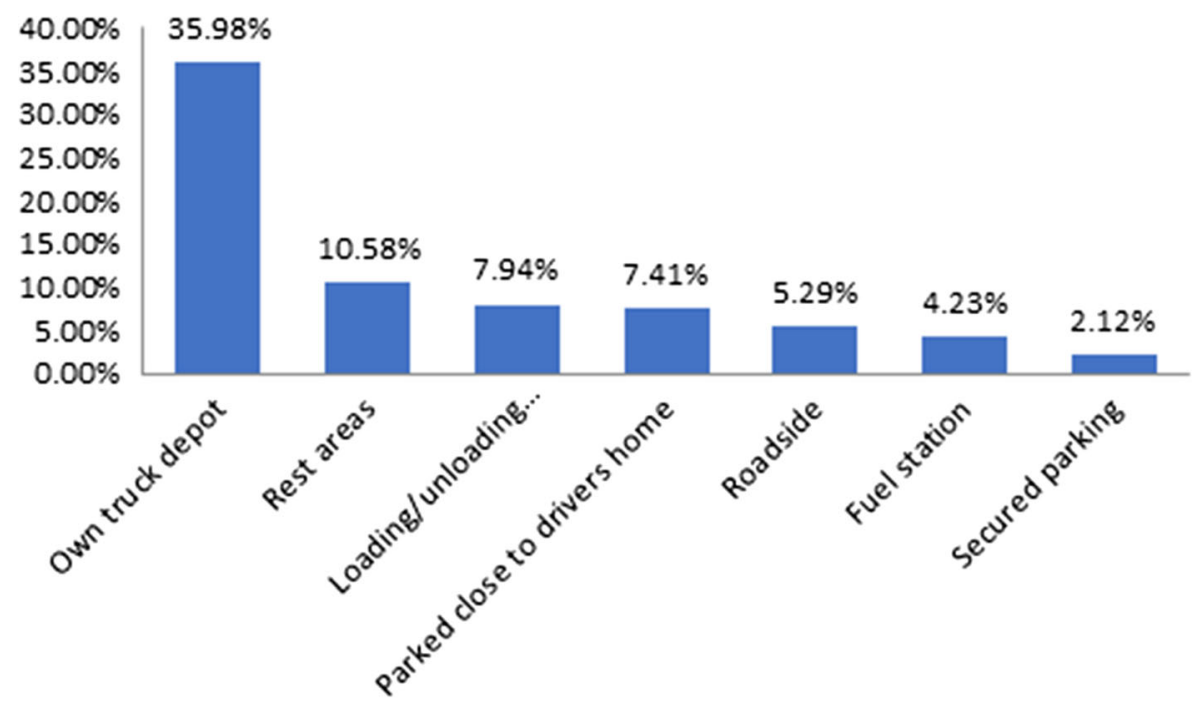

Fig. 8 Preferred locations for stealing fuel from trucks 


\section{Security measures}

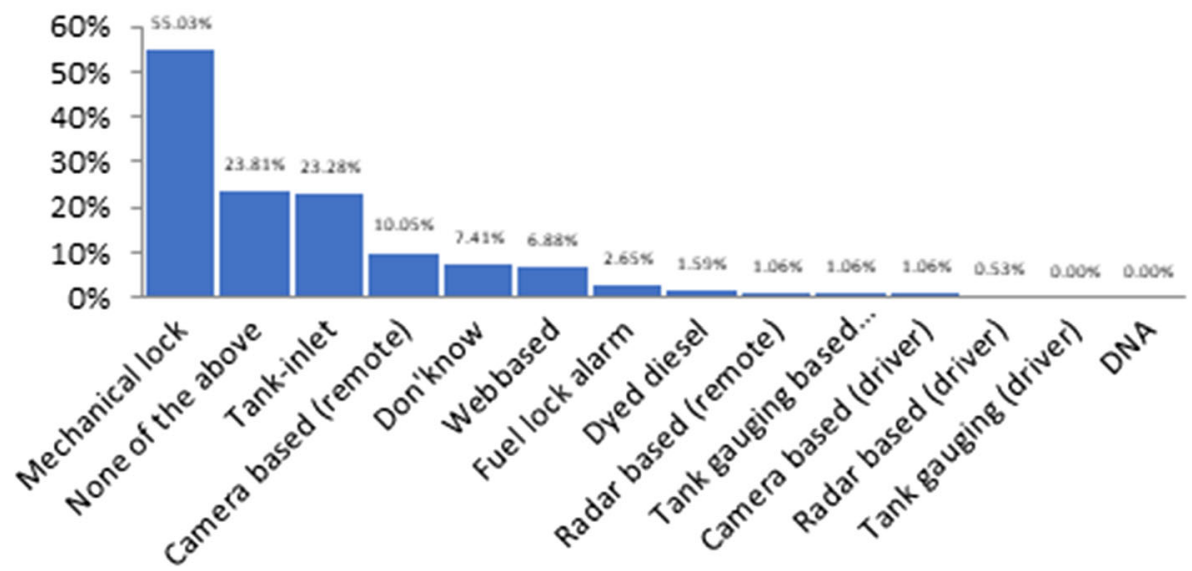

Fig. 9 Used security measures for fuel theft protection

\section{Impacts of Security measures}

Figure 10 reports the distribution of scores of the remaining solutions, and Fig. 11 the average scores. Mechanical locks for fuel caps have on average a "bad performance" $(\mathrm{M}=2.39$, “Bad"), despite a good majority of respondents is actually using this solution. Perceptions about the effectiveness of the most of the solutions seem to be positive, between 4 Good and 5 Very Good (Fig. 10). Specifically, tank gauging ( $\mathrm{M}=$ 4.5 driver alerted, $M=4$ remote monitored), proximity radars $(M=4$ radar remote monitored, $\mathrm{M}=3.83$ radar driver alerted), tampering alarms installed on fuel tank locks $(\mathrm{M}=3.89)$, tank inlets, DNA based solutions, and cameras all scores above 3 .

\section{Discussion and conclusion}

This study proposes a descriptive analysis of the fuel theft phenomenon in Sweden, as experienced by road carriers. Very little data about fuel theft is available to researchers and decision makers. Hence, by means of a survey, this study (response rate 18.9\%) aims to shed light on the phenomenon. In addition, it aims to enhance understanding about what anti-theft devices are being used by carriers and what is the perceived efficacy of these systems.

Results show that annually about 150,225 1 of fuels have been stolen from Swedish road carriers, corresponding to approximately 8001 of diesel per company fleet. Companies affected by the problem experience fuel theft up to 20 events per year (1.6 per month). The crime hot spot analysis shows that fuel theft activities are concentrated in geographical hot spots, mainly in the most populated regions in Sweden, Västra Götaland and Stockholm, where road transport is more intense. This is in accordance with previous research, pointing out at the importance of seasonality, high traffic locations and concentration of crime activities in hot spots (Ekwall and Lantz 2013). At the same time, the data in this study show that when trucks are parked in in unsecured parking areas, the risk for fuel theft increases significantly. Regarding the modus operandi, it seems to be very simple to steal 


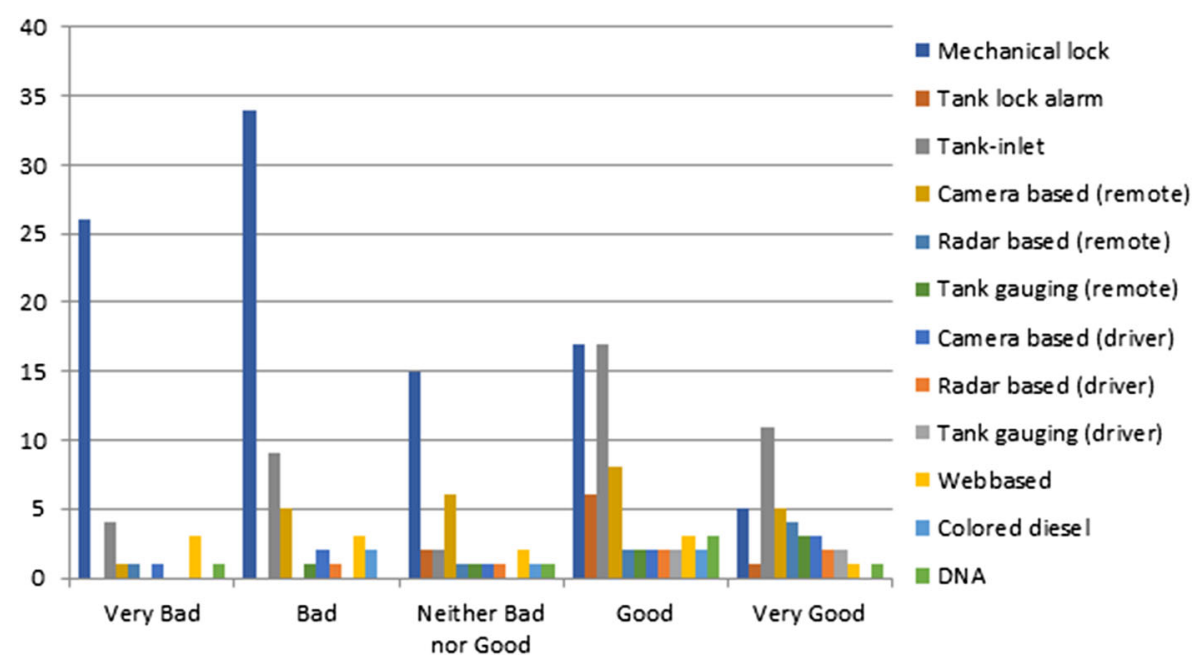

Fig. 10 Perceived impacts of security measures ( $1=$ Very Bad to $5=$ Very Good $)$

diesel from trucks, i.e. by simply tampering fuel cap locks and syphoning. The majority of the surveyed road carriers seem to use locks to avoid the unauthorized fuel cap removal, despite performance is scarce. On the opposite, solutions that are believed to perform better include those based on tank gauging, radar sensors, alarms, cameras, DNA marking of fuel. However, these are scarcely adopted.

From a theoretical viewpoint, this study contributes with additional knowledge about the potential existence of the problem. Results are also well aligned with existing research in the criminology area, where criminals follow rational choices attacking targets that are more vulnerable in location where logistics and transport operations are more intense (Cohen and Felson 1979; Ekwall and Lantz 2013). From a practical viewpoint, this research provides road transport carriers with enhanced knowledge about crime spots in Sweden, as well as

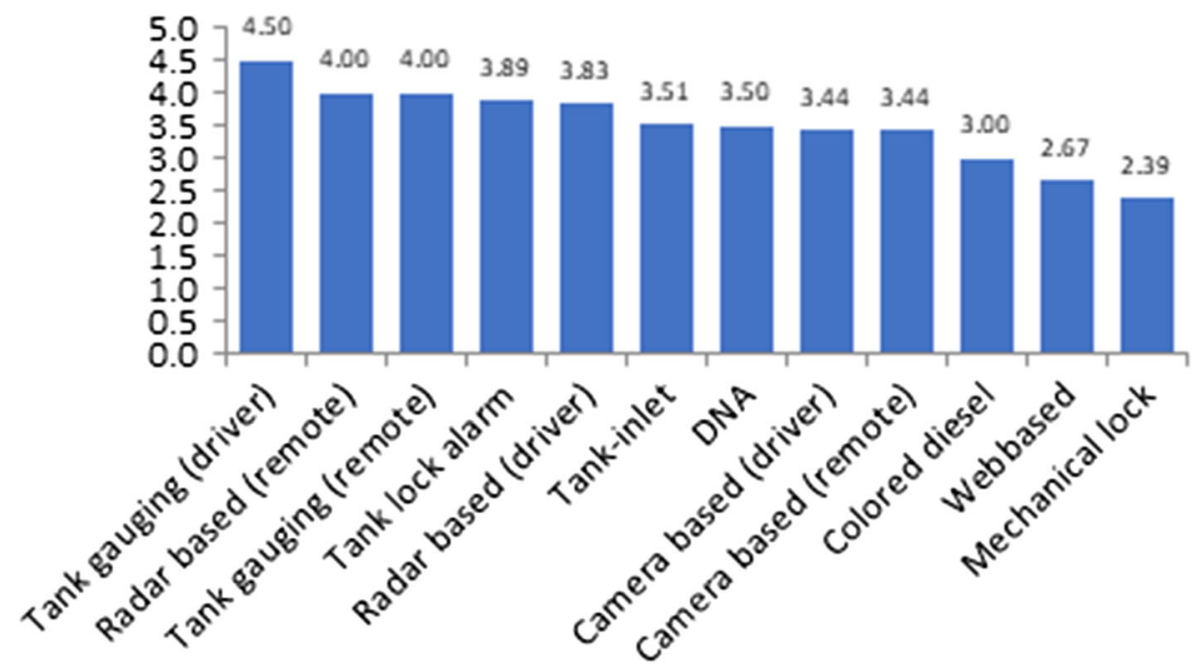

Fig. 11 Average impact scores of security measures for fuel theft (Likert scale from $1=$ Very bad to $5=$ Very good) 
with data about the potential impacts of existing anti-theft devices. The modus operandi described in this study, could support technology providers and truck manufacturers, in order to develop more robust solutions. For instance, the automotive industry is recommended to build-in security of fuel by designing protecting frames of tanks, vents and supply lines, without leaving any vulnerable spots. Finally, this study highlights that fuel theft risks increase when parking in non-secured spots. Hence, security cannot be guaranteed merely by protecting the tank on the vehicle, but it needs to be complemented by enhanced security of the areas where the trucks are parked. For instance, security measures should involve good practices, security guards, and additional technologies to be installed in parking areas and terminal depots, e.g. CCTV (Closed Circuit TeleVision), alarms, access control etc. In this aspect, existing research has pointed out the importance of increasing the number of secure parking areas, and the European commission is currently working to incentivize the construction and usage of high quality and secure parking areas (EU 2013; Regeringen 2018). The results from this study could be used to determine the magnitude of the phenomenon and most of all in which regions these secured areas should be prioritized.

The analysis of the results raises concerns about the potential reasons behind the lack of security against fuel theft. To steal diesel, criminals are relying on very simple approaches, i.e. tampering the fuel cap lock and syphoning. Hence, future studies should aim to understand the reasons behind the failure of existing technologies and work towards innovative solutions. Future research should also investigate further the cost of security and companies' willingness to pay to protect their vehicles against fuel theft.

Funding Information Open access funding provided by Royal Institute of Technology.

Open Access This article is licensed under a Creative Commons Attribution 4.0 International License, which permits use, sharing, adaptation, distribution and reproduction in any medium or format, as long as you give appropriate credit to the original author(s) and the source, provide a link to the Creative Commons licence, and indicate if changes were made. The images or other third party material in this article are included in the article's Creative Commons licence, unless indicated otherwise in a credit line to the material. If material is not included in the article's Creative Commons licence and your intended use is not permitted by statutory regulation or exceeds the permitted use, you will need to obtain permission directly from the copyright holder. To view a copy of this licence, visit http://creativecommons.org/licenses/by/4.0/.

\section{References}

Ageeva S, Suslov N (2009) Influence of energy prices on the size of shadow economy: a cross country analysis. EERC Research Network, Russia and CIS

Anderson B (2007) Securing the Supply Chain. Prevent Cargo Theft Sec 44:56-58

Bennett S (2012) Medium/heavy duty truck engines, fuel \& computerized management systems. Cengage Learning Bitzenis A, Kontakos P (2014) Energy trade and tax evasion in the oil sector in Greece. In: 7th Annual Conference of the EuroMed Academy of Business

Burges D (2012) Cargo theft, loss prevention, and supply chain security. Butterworth-Heinemann

Chen Y-H, Chen S-L, Wu C-h (2005) The Impact of Stowaways and Illegal Migrants by Sea-a case study in Taiwan Proceedings of the International Association of Maritime Universities (IAMU), 24th-26th October

Chopra S, Sodhi MS (2004) Managing risk to avoid supply-chain breakdown MIT Sloan management review 46:53 Cochran WG (2007) Sampling techniques. Wiley

Cohen LE, Felson M (1979) Social change and crime rate trends: A routine activity approach American sociological review:588-608 
Corbett JJ, Wang H, Winebrake JJ (2009) The effectiveness and costs of speed reductions on emissions from international shipping. Transp Res Part D: Transp Environ 14:593-598

Crone M (2007) Are global supply chains too risky?: a practitioner's perspective logistics management 46

Ekwall D, Lantz B (2013) Seasonality of cargo theft at transport chain locations. Int J Phys Distrib Logist Manag 43:728-746

van den Engel AW, Prummel E (2007) Organised theft of commercial vehicles and their loads in the EUROPEAN UNION. Policy Department Structural and Cohesion Policies

EU (2010) Resolution on preventing and combating road freight crime and providing secure truck parking areas. Brussels

EU (2013) REGULATION (EU) No 1315/2013 OF THE EUROPEAN PARLIAMENT AND OF THE COUNCIL of 11 December 2013 on Union guidelines for the development of the trans-European transport network and repealing Decision No 661/2010/EU

EUParliament (2007) Organised theft of commercial vehicles and their loads in the European Union - Rep. No. 610. Brussels, Belgium

Fennelly L (2012) Handbook of loss prevention and crime prevention. Elsevier.

Geddie J, Khasawneh R (2018) Over \$40 million of fuel stolen from Shell refinery, Singapore court docs show. https:/www.reuterscom/article/singapore-oil-theft/over-40-million-of-fuel-stolen-from-shellrefinery-singapore-court-docs-show-idUSL5N1ST230. Accessed May 2018

Giannakis M, Louis M (2011) A multi-agent based framework for supply chain risk management. J Purch Supply Manag 17:23-31

IRU (2009) IRU analysis of the dramatic increase in pirate and organised crime attacks on truck drivers in European parking areas \& on roads

Lee HL, Wang S (2005) Higher supply chain security with lower costs: lessons from total quality management. Int J Prod Econ 96:289-300

Lun YV, Wong CW, Lai KH, Cheng T (2008) Institutional perspective on the adoption of technology for the security enhancement of container transport. Transp Rev 28:21-33

Männistö T, Hintsa J, Urciuoli L (2014) Supply Chain Crime-Taxonomy development and empirical validation. Int J Ship Trans Log 6:238-256

Notteboom TE, Vernimmen B (2009) The effect of high fuel costs on liner service configuration in container shipping. J Transp Geogr 17:325-337

Regeringen (2018) Regeringen vill ha fler säkra uppställningsplatser för yrkestrafiken

Reggiani A (2013) Network resilience for transport security: some methodological considerations. Transp Policy 28:63-68

Sheffi Y (2001a) Supply chain management under the threat of international terrorism. Int J Log Manag 12:1-11

Sheffi Y (2001b) Supply chain management under the threat of international terrorism. Int J Logist Manag 12:1-11

Simchi-Levi D, Snyder L, Watson M (2002) Strategies for uncertain times. Sup Chain Manag Rev 6:11-12

Sternberg H, Nyquist C, Nilsson F (2012) Enhancing security through efficiency focus-Insights from a multiple stakeholder pilot implementation. J Bus Logist 33:64-73

Talarico L, Zamparini L (2017) Intermodal transport and international flows of illicit substances: Geographical analysis of smuggled goods in Italy. J Transp Geogr 60:1-10

TAPA (2017) TSR (Trucking Security Requirements), https://www.tapa-global.org/fileadmin/public/downloads/TSR/TAPA_TSR_2017_Final.pdf

TAPA (2018) TAPA's secure parking programme targets initial group of 520 sites in 35 countries. https://www.tapaemea.org/news-detail-view/tapas-secure-parking-programme-targets-initial-group-of520-sites-in-35-countries.html. Accessed 23 January 2018

Taye D (2018) Illicit trade creates fuel shortage. Ethiopia. https://www.thereporterethiopia.com/article/illicittrade-creates-fuel-shortage

Urciuoli L (2010) Supply chain security — mitigation measures and a logistics multi-layered framework. J Transp Secur 3:1-28

Urciuoli L (2011) Investing in transport security solutions: using the quantitative risk assessment (QRA) approach. Int J Risk Asses Manag 15:275-298

Urciuoli L (2016) What are the causes of transport insecurity? Results from a survey with transport operators. Transp Policy 47:189-202

Urciuoli L, Hintsa J (2016a) Adapting supply chain management strategies to security-an analysis of existing gaps and recommendations for improvement International Journal of Logistics Research and Applications:1-20 
Urciuoli L, Hintsa J (2016b) Differences in security risk perceptions between logistics companies and cargo owners. Int J Log Manag 27:418-437

Viswanadham N, Gaonkar RS (2008) Risk management in global supply chain networks. In: Supply Chain Analysis. Springer, pp 201-222

Wu P-J, Chen M-C, Tsau C-K (2017) The data-driven analytics for investigating cargo loss in logistics systems. Int J Phys Distrib Logist Manag 47:68-83

Publisher's note Springer Nature remains neutral with regard to jurisdictional claims in published maps and institutional affiliations. 